\title{
Introducing Point-Counterpoint Perspectives in the Journal of Hospital Medicine
}

\author{
Samir S Shah, MD, MSCE, ${ }^{1 \star}$ Sanjay Mahant, MD, MSc, ${ }^{2}$ Nita Kulkarni, MD, ${ }^{3}$ Tara Lagu, MD, MPH 3,4
}

'Division of Hospital Medicine, Cincinnati Children's Hospital Medical Center, Cincinnati, Ohio; ${ }^{2}$ Division of Pediatric Medicine, Department of Pediatrics, University of Toronto and The Hospital for Sick Children, Toronto, Ontario, Canada; ${ }^{3}$ Division of Hospital Medicine, Northwestern University Feinberg School of Medicine, Chicago, Illinois; ${ }^{4}$ Center for Health Services \& Outcomes Research, Institute for Public Health and Medicine, Northwestern University Feinberg School of Medicine, Chicago, Illinois.

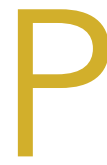

roviding high-quality, efficient, and evidence-based healthcare is a complicated and complex process. The right approach or path forward is not always clear. In medicine, decision-making inherently involves uncertainty; evidence may be lacking, or values or context may differ, and thus, reasonable clinicians may choose to make different decisions based on the same data.

In this spirit of fostering education and healthy debate to improve understanding of challenges relevant to the field of hospital medicine, we are pleased to introduce our Point-Counterpoint series within the Perspectives in Hospital Medicine section of the journal. Point-Counterpoint Perspectives presents a debate by content experts. Each provides an interpretation of evidence regarding patient management or other controversial issues relating to hospital-based care. The format consists of an overview of the topic with an original point followed by a counterpoint response and, finally, a rebuttal (Table). We ask contributors to be as outspoken in their points and counterpoints as the evidence allows in order to fully elaborate the questions and uncertainties that may otherwise be familiar only to experts in the field or to those in other disciplines.

Our inaugural point-counterpoint articles address whether healthcare workers should receive priority for scarce drugs and therapies during the coronavirus disease 2019 (COVID-19) pandemic. The intermittent shortage of medical supplies and protective equipment has made it not only difficult but also at times dangerous for healthcare workers to care for infected patients. ${ }^{1}$ The risks of developing COVID-19 and fear of transmitting it to loved ones has led to stress, fatigue, and burnout among healthcare workers, leading some to quit and even

*Corresponding Author: Samir S Shah, MD, MSCE; Email: Samir.Shah@cchmc.org; Telephone: 513-636-6222; Twitter: @SamirShahMD

Published online first February 17, 2021.

Received: January 25, 2021; Accepted: January 26, 2021

(c) 2021 Society of Hospital Medicine DOI 10.12788/jhm.3601
TABLE. Point-Counterpoint Perspectives Formatting Guidance

\begin{tabular}{ll}
\hline Section & Requirements \\
\hline Title & $\begin{array}{l}\text { Include the words Point, Counterpoint, or Rebuttal as part of the title. For example, } \\
\text { "Counterpoint: Prioritizing Healthcare Workers for Scarce Critical Care Resources Is } \\
\text { Impractical and Unjust" }\end{array}$ \\
\hline Abstract & None \\
\hline Text & $\begin{array}{l}\text { Point: } 1,500 \text { or fewer words and } 10 \text { or fewer references } \\
\text { Counterpoint: } 1,500 \text { or fewer words and } 10 \text { or fewer references } \\
\text { Rebuttal: } 600 \text { or fewer words, including references }\end{array}$ \\
\hline
\end{tabular}

attempt suicide. The downstream effects of this stress may adversely affect patients and exacerbate staffing challenges in an already taxed healthcare system. ${ }^{2}$ Do we have a special obligation to those on the front lines? We are grateful to Drs Kirk R Daffner, Armand Antommaria, and Ndidi I Unaka, for addressing this controversial topic. ${ }^{3-5}$

Disclosures: The authors reported no conflicts of interest or financial relationships relevant to this manuscript.

\section{References}

1. Lagu T, Artenstein AW, Werner RM. Fool me twice: the role for hospitals and health systems in fixing the broken PPE supply chain. J Hosp Med. 2020;15(9):570-571. https://doi.org/10.12788/jhm.3489

2. Ali SS. Why some nurses have quit during the coronavirus pandemic. NBC News. May,10, 2020. Accessed January 18, 2021. https://www.nbcnews.com /news/us-news/why-some-nurses-have-quit-during-coronavirus-pandemic $-n 1201796$

3. Daffner KR. Point: healthcare providers should receive treatment priority during a pandemic. J Hosp Med. 2021;16(3):180-181. https: //doi.org/10.12788/jhm.3596

4. Antommaria A, Unaka NI. Counterpoint: prioritizing healthcare workers for scarce critical resources is impractical and unjust. J Hosp Med. 2021;16(3):182183. https://doi.org/10.12788/jhm.3597

5. Daffner KR. Rebuttal: accounting for the community's reciprocal obligations during a pandemic. J Hosp Med. 2021;16(3):184. https: //doi.org/10.12788/jhm.3600 